\title{
Outcome after vertebral fractures with neurological lesion treated either surgically or conservatively in Spain
}

\author{
P Bravo MD, C Labarta MD, MA Alcaraz MD, J Mendoza MD, A Verdu MD \\ Hospital Nacional de Paraplejicos, Toledo, Spain.
}

Out of 245 patients with spinal cord injury admitted to the Hospital Nacional de Paraplejicos of Toledo (110 treated conservatively, 135 treated surgically), randomised samples of 48 cases treated conservatively and 75 treated surgically were selected for comparison. Improved neurological status according to the Frankel scale was achieved in $37.5 \%$ after conservative treatment, and in $23 \%$ after surgery. Reduction and stabilisation were achieved by both conservative and surgical methods, and the functional outcome was the same for both treatments. The mean hospitalisation time was $198 \pm 10$ (mean $\pm \mathrm{SE}$ ) days for patients treated with conservative measures, and $222 \pm 9$ days for patients treated surgically. No correlation was found between the type of fracture and severity of the neurological lesion. The neurological outcome by type of fracture was also similar for both treatments. No correlation was found between the degree of vertebral wedging and neurological evolution. Patients with greater vertebral displacement showed a worse neurological outcome.

Taking both groups as a whole, incomplete lesions showed improvement in $66 \%$, and complete in $14 \%$. Neurological improvement after incomplete lesions was found in $87.5 \%$ of patients under 25 years of age and in $47 \%$ of those over 25 years. The poorest rate of improvement was found in those with thoracic lesions $(17 \%)$, while those with cervical lesions improved most $(48 \%)$. Furthermore, the neurological outcome in patients who were surgically treated within the first 24 hours after the injury was not statistically different from those who were treated later.

Keywords: spinal cord injury; neurological recovery; conservative treatment; surgical treatment.

\section{Introduction}

The relative benefits of conservative and surgical treatment in the management of traumatic spinal cord lesions are still controversial. Some authours recommend conservative treatment, ${ }^{1-4}$ some prefer surgical treatment $^{5-10}$ and others state that it may occasionally be necessary to use surgical treatment for lumbar and thoracic spinal fractures. ${ }^{11,12}$

This longtime unresolved discussion very likely indicates that there is a lack of significant difference between the two forms of treatment. The present study describes the results obtained using both treatments for spinal cord injury in the Hospital Nacional de Paraplejicos of Spain. An attempt has been made to clarify whether either of the two treatment strategies is clearly better.

\section{Materials and methods}

We have made a retrospective comparative study of patients with spinal cord injuries treated by surgical or conservative measures. Both groups include patients aged between 16 and 56 years old with injury resulting from trauma admitted to the Hospital Nacional de Paraplejicos from January 1989 to September 1991. Time lapse from injury to admission to our hospital was less than 30 days. Patients with spinal cord injuries between T1 and T4 were excluded from the study. From a total of 245 cases, $110(45 \%)$ received conservative 
treatment, and $135(55 \%)$ were treated surgically. Randomised samples of 48 patients treated conservatively and 75 patients treated surgically were employed to make the comparative analysis, and are fully described in this paper.

The variables studied were: age; time elapsed from lesion to hospital admission; lesion level: cervical, thoracic (T5-T10), thoracolumbar (T11-L1) and lumbar (below L1); type of lesion (complete or incomplete); aetiology; type of fracture (compression, flexion-rotation and hyperextension); Frankel score on admission and discharge ${ }^{2}$ score on the Toledo functionality scale; and radiological data on admission and discharge (vertebral wedging and dislocation). For scoring on the Toledo scale on discharge, the following categories are defined: $\mathrm{a}=$ completely dependent; $\mathrm{b}=$ partially dependent; $\mathrm{c}=$ independent in a wheelchair; $d=$ wheelchair alternating with two crutches; $\mathrm{e}=$ totally independent with or without two crutches. The percentage of vertebral wedging was defined as $(100-\mathrm{BA} / \mathrm{BP})^{*} 100$, where BA and BP are, respectively, the height in millimetres of the anterior and posterior aspects of the fractured vertebral body. The percentage of dislocation is defined as the ratio of the distance of rear dislocation of the fractured vertebra in millimetres divided by the normal width of the vertebra immediately below the fractured vertebra; this is then multiplied by 100 .

Conservative treatment employed for thoracic and lumbar fractures was based on postural measures, following the techniques described by Guttmann, ${ }^{1}$ over a period of 6-8 weeks. Cervical fractures were treated by continuous cervical traction over 6-8 weeks with $6-8 \mathrm{~kg}$ weight, followed by a neck collar for maintenance during 6-8 weeks. The operations carried out were: fixation in $63(84 \%)$; laminectomy in 5 $(7 \%)$; laminectomy together with fixation in $7(9 \%)$. Fixation modalities included: Harrington rods in $14(22 \%)$; modified Harrington rods in $16(26 \%)$; 'Malaga' vertebral fixator in $24(38 \%)$; Cloward procedure in 9 $(14 \%)$ who suffered a cervical injury. Harrington rods were also employed in the 7 patients treated by laminectomy together with fixation. The 'modified' Harrington rods group includes those patients who were treated additionally with sublaminar wiring. Recently, we have successfully used the 'Malaga' transpedicular fixator, which is similar to Dick instrumentation (two pairs of Schanz screws placed in the pedicles and connected by threaded rods).

Twenty-nine $(39 \%)$ of the 75 patients treated surgically were operated on in our hospital, while $46(61 \%)$ were operated on in other centres before admission to our hospital. No operation of laminectomy was performed at our centre. Our treatment of choice is usually conservative, and surgical treatment is considered only for fractures with luxation of more than $1 / 3$ of vertebral displacement and rupture of interspinous ligaments.

The statistical analysis included the comparison of mean values (Student's $t$ test), and chi-square test and confidence interval of percentages $(95 \% \mathrm{Cl})$ in the case of qualitative variables. In order to control for possible confounding factors, stratified tables with odds ratios, Cornfield confidence intervals at $95 \%$, and MantelHaenszel chi-square and pounded odds ratios were employed. A $95 \%$ confidence interval around an odds ratio that does not include 1.0 implies a statistically significant difference in the likelihood of an outcome, without confusion by the stratified factor. ${ }^{13}$

\section{Results}

The main features of both study groups are shown in Table I. Both groups are homogenous in terms of age, time lapse to admission, amplitude of spinal lesion, type of fracture and aetiology. The number of thoracolumbar cases treated surgically (39) is significantly greater than those treated conservatively (9). The difference could be due to the fact that orthopaedic surgeons are more prone to operate at this level. Of all patients, $21 \%$ were admitted to our hospital within the first 24 hours after the time of the injury, and the rest thereafter. Complete lesions were found in $88(72 \%)$ patients, while $35(28 \%)$ had incomplete lesions. Traffic accidents were the cause of $69(56 \%)$ of the spinal injuries. 
Table I Main features of each study group

\begin{tabular}{|c|c|c|c|}
\hline Characteristic & $\begin{array}{c}\text { Conservative } \\
(n=48)\end{array}$ & $\begin{array}{l}\text { Surgical } \\
(n=75)\end{array}$ & $\begin{array}{l}\text { Significance } \\
(\text { Value } p)\end{array}$ \\
\hline Age & $26.7 \pm 1.3^{\mathrm{a}}$ & $28.3 \pm 1$ & $p=0.20 \mathrm{NS}$ \\
\hline Time lapse to admission & $12.4 \pm 1.5$ & $10.7 \pm 0.9$ & $p=0.35 \mathrm{NS}$ \\
\hline \multicolumn{4}{|l|}{ Vertebral level } \\
\hline $\begin{array}{l}\text { Thoracic } \\
\text { (T5-T10) }\end{array}$ & 23 & 19 & \multirow{3}{*}{$\begin{array}{c}X^{2}[3]=24 \\
p=0.00002 \\
p<0.001\end{array}$} \\
\hline $\begin{array}{l}\text { Thoracolumbar } \\
\text { (T11, T12, L1) }\end{array}$ & 9 & 39 & \\
\hline Lumbar & 0 & 8 & \\
\hline \multicolumn{4}{|l|}{ Spinal injury } \\
\hline Complete & 33 & 55 & $X^{2}[1]=0.12$ \\
\hline Incomplete & 15 & 20 & $p=0.73 \mathrm{NS}$ \\
\hline \multicolumn{4}{|l|}{ Type of fracture } \\
\hline Compression & 12 & 23 & \\
\hline Flexion-rotation & 35 & 52 & $X^{2}[2]=1.9$ \\
\hline Hyperextension & 1 & 0 & $p=0.4 \mathrm{NS}$ \\
\hline \multicolumn{4}{|l|}{ Cause of lesion } \\
\hline Traffic & 33 & 36 & \\
\hline Work & 6 & 18 & $X^{2}[2]=5$ \\
\hline Other & 9 & 21 & $p=0.07 \mathrm{NS}$ \\
\hline
\end{tabular}

${ }^{a}$ Mean \pm SE.

Chi-square test has been used for qualitative variables.

Classification of skeletal injuries was based on Holdsworth's system. ${ }^{14}$ Among those spinal injuries due to compression, $64 \%$ were found to be typical compression fractures, while $36 \%$ were crush fractures. Among the fractures due to flexion-rotation, $71 \%$ had dislocations. The mean time from the moment of sustaining the lesion to surgical operation was $7.5 \pm 1.2$ days $(\mathrm{M} \pm \mathrm{SE})$. The mean follow up time from admission to discharge in the whole population was $213 \pm 7$ days.

\section{Neurological evolution}

The neurological findings graded according to the Frankel scale on admission and discharge were compared for both groups (Table II). Among patients treated conservatively, $37.5 \%(95 \% \mathrm{Cl}=23.8-51 \%)$, improved their neurological status compared with $23 \%(13-32 \%)$ of those treated surgically. Neurological improvement was observed in $18 \%(5-31 \%)$ of the patients with complete lesions treated conserv- atively, and in $11 \%(3-19 \%)$ of those treated surgically. Those with an incomplete lesion showed improvement in $80 \%$ $(56-100 \%)$ after conservative treatment, and in $55 \%(33-77 \%)$ after surgical treatment. When both groups are considered together, $28 \%(20.4-36.4 \%)$ of the patients showed improvement.

The neurological evolution of the patients, depending on the level of the spinal injury, is shown in Table III. Patients with cervical injuries had a greater degree of neurological improvement (48\%, $\mathrm{Cl}=28.4-67.6 \%)$ than those with thoracic $(17 \%, \quad \mathrm{Cl}=5.4-27.9 \%)$, thoracolumbar $(27 \%, \mathrm{Cl}=14.5-39.7 \%)$ or lumbar injuries $(37 \%, \mathrm{Cl}=4-71 \%) X^{2}[3]=7.9, p<0.05$. Complete thoracic and thoracolumbar injuries showed the lowest improvement rates ( $8 \%$ and $11 \%$ respectively). On the other hand, incomplete thoracic injuries showed the higher improvement rate $(80 \%)$, although the number of patients in this group was small. Improvement was greater in those with incomplete lesions than in those 
Table II Distribution of the Frankel scale at admission and discharge in patients with (a) conservative and (b) surgical treatment

a

\begin{tabular}{llllll}
\hline & A & B & C & D & E \\
\hline A & 27 & 2 & & 3 & 1 \\
B & & 3 & & 3 & \\
C & & & & 9 & \\
D & & & & & \\
E & & & & & \\
\hline
\end{tabular}

b

\begin{tabular}{llllll}
\hline & A & B & C & D & E \\
\hline A & 49 & 1 & 2 & 3 & \\
B & & 7 & 1 & 3 & \\
C & & & 1 & 7 & \\
D & & & & 1 & \\
E & & & & & \\
\hline
\end{tabular}

Table III Frankel scale distribution at admission and discharge in patients according to vertebral level of lesion: (a) cervical, (b) thoracic, (c) thoracolumbar (D11, D12, L1) and (d) lumbar a

\begin{tabular}{|c|c|c|c|c|c|}
\hline & A & B & C & $\mathrm{D}$ & $\mathrm{E}$ \\
\hline A & 9 & 1 & & 2 & \\
\hline B & & 4 & & 3 & \\
\hline C & & & & 6 & \\
\hline D & & & & & \\
\hline$E$ & & & & & \\
\hline
\end{tabular}

c

\begin{tabular}{lllllll} 
& A & B & C & D & E \\
\cline { 3 - 6 } A & 31 & 1 & 1 & 1 & 1 \\
B & & 3 & 1 & 1 & \\
C & & & 1 & 7 & \\
D & & & & & \\
E & & & & & \\
\hline
\end{tabular}

with complete lesions for all levels of injury, except for injuries below L1, where no statistically significant differences were found, although the number of patients in this group was also small.

Neurological status (improved vs without change) for each group in relation to age. level, type of fracture, displacement and wedging is shown in Table IV. Of 55 patients aged under 25 years, $38 \%$ showed improvement, while in 68 older patients improvement was observed in $21 \%$, $\left(X^{2}[1]=4.6, p<0.05\right)$. Nevertheless, the stratified analysis by the type of treatment showed a similar neurological outcome for both treatments in the two age groups. The logit combined estimate of the odds ratio b

\begin{tabular}{llllll}
\hline & A & B & C & D & E \\
\hline A & 34 & 2 & 1 & & \\
B & & 1 & & 2 & \\
C & & & & 2 & \\
D & & & & & \\
E & & & & & \\
\hline
\end{tabular}

d

\begin{tabular}{llllll}
\hline & A & B & C & D & E \\
\hline A & 2 & & & 2 & \\
B & & 2 & & 1 \\
C & & & & 1 \\
D & & & & \\
E & & & \\
\hline
\end{tabular}

(OR) was found to be $0.53 \quad(\mathrm{Cl}=$ $0.13-1.13)$. This discordance may be due to the fact that the neurological outcome after incomplete lesions was better in patients under 25 years $(87.5 \%)$ than in those who were older $(47 \%),\left(X^{2}[1]=4.5, p<0.05\right)$. The neurological outcome after complete lesions was the same for both age groups.

No statistical differences were found in the neurological evolution for both treatments in patients with cervical, thoracic and thorocolumbar injuries (Table IV). Patients with lesions below L1 were not analysed because their number was too small. There was no statistical association between fracture type and neurological outcome. The latter, according to the type of fracture, was 
Table IV Neurological status (expressed as number of cases, odds ratio and chi-square of Mantel-Haenszel) for each study group in relation to age, level of lesion, type of fracture and percentages of vertebral displacement and wedging

\begin{tabular}{|c|c|c|c|c|c|c|}
\hline & \multicolumn{4}{|c|}{ Treatment } & \multirow[b]{3}{*}{ Odds ratio $(\mathrm{CI})^{\mathrm{a}}$} & \multirow[b]{3}{*}{ Significance } \\
\hline & \multicolumn{2}{|c|}{ Surgical } & \multicolumn{2}{|c|}{ Conservative } & & \\
\hline & Improvement & Without change & Improvement & Without change & & \\
\hline \multicolumn{7}{|l|}{ Age } \\
\hline Under 25 & 10 & 20 & 11 & 14 & $0.64(0.18-2.18)$ & $p=0.18^{b}$ \\
\hline Over 25 & 7 & 38 & 7 & 16 & $0.42(0.11-1.62)$ & $\mathrm{OR}_{\mathrm{M}-\mathrm{H}}=0.53 \mathrm{Cl}(0.22-1.28)^{\mathrm{c}}$ \\
\hline \multicolumn{7}{|l|}{ Level } \\
\hline Cervical & 4 & 5 & 8 & 8 & $0.80(0.11-5.5)$ & $p=0.09$ \\
\hline Thoracic & 1 & 18 & 6 & 17 & $0.16(0.01-1.6)$ & $\mathrm{OR}_{\mathrm{M}-\mathrm{H}}=0.39 \mathrm{Cl}(0.13-1.13)$ \\
\hline Thoracolumbar & 9 & 30 & 4 & 5 & $0.38(0.07-2.14)$ & \\
\hline \multicolumn{7}{|l|}{ Type of fracture } \\
\hline Flexion-rotation & 10 & 42 & 13 & 22 & $0.40(0.14-1.18)$ & $p=0.15$ \\
\hline Compression & 7 & 16 & 4 & 8 & $0.88(0.16-5)$ & $\mathrm{OR}_{\mathrm{M}-\mathrm{H}}=0.51 \mathrm{Cl}(0.21-1.23)$ \\
\hline \multicolumn{7}{|l|}{ Displacement } \\
\hline$<30 \%$ & 13 & 12 & 16 & 17 & $1.5 \quad(0.36-3.71)$ & $p=0.85$ \\
\hline$>30 \%$ & 4 & 46 & 2 & 13 & $0.57(0.07-5)$ & $\mathrm{OR}_{\mathrm{M}-\mathrm{H}}=0.98 \mathrm{Cl}(0.35-2.73)$ \\
\hline \multicolumn{7}{|l|}{ Wedging } \\
\hline$<30 \%$ & 11 & 29 & 10 & 13 & $0.49(0.15-1.65)$ & $p=0.1$ \\
\hline$>30 \%$ & 6 & 29 & 8 & 17 & $0.44(0.11-1.72)$ & $\mathrm{OR}_{\mathrm{M}-\mathrm{H}}=0.47 \mathrm{Cl}(0.19-1.13)$ \\
\hline
\end{tabular}

${ }^{\mathrm{a}} \mathrm{CI}=95 \%$ confidence intervals.

${ }^{b}$ Chi-square of Mantel-Haenszel.

cPounded odds ratio of Mantel-Haenszel with $95 \%$ confidence interval. 
the same for both treatment modalities (the unique patient with a hyperextension fracture was not included in the analysis). Patients with vertebral displacement on admission above $30 \% \quad(n=65)$ showed a worse neurological evolution, $6(9 \%)$ than did those with vertebral displacements under $30 \% \quad(n=58)$, of which $29(50 \%)$ showed a favourable evolution $\left(X^{2}[1]=24\right.$, $p<0.001)$. The neurological outcome according to the percentage of vertebral displacement was the same for both types of treatment. The degree of vertebral wedging did not have any influence on the neurological outcome.

If we consider the patients treated surgically, no statistically significant differences with respect to the neurological outcome were found between those operated before the first 24 hours after the time of the injury $(n=31) 9(29 \%)$, and those operated thereafter $(n=44) 8(18 \%), X^{2}[1]=1.2$.

\section{Radiological examination}

Table V shows the mean values of vertebral wedging and displacement in both groups. We have found that the modality of treatment has no statistically significant influence in the wedging percentage. The percentage of vertebral displacement in both study groups was statistically smaller on discharge than on admission.

\section{Functional evolution expressed on the Toledo scale}

Table VI shows the functional state attained by patients according to type of treatment as scores on the Toledo scale. There were no overall statistically significant differences

Table V Percentages (mean $\pm \mathrm{SE}$ ) of wedging and vertebral displacement in each study group

\begin{tabular}{lrr}
\hline & Conservative & Surgical \\
\hline Wedging & & \\
At admission & $33.3 \pm 2.4$ & $37.9 \pm 3.3$ \\
On discharge & $36 \pm 2.3$ & $37.7 \pm 3.4$ \\
Displacement & & \\
At admission & $17.9 \pm 1.7$ & $30.6 \pm 2.2$ \\
On discharge & $6.5 \pm 0.6$ & $8.8 \pm 0.8$ \\
\hline
\end{tabular}

between the two main categories of treatment $\left(X^{2}[4]=8\right)$. More patients at $d$ grade were found among those who had been treated surgically $(35(76 \%))$ as compared to the $11(24 \%)$ of those treated conservatively. This is due to the fact that there were more cases of thoracolumbar and lumbar injury in the group treated surgically, 47 $(63 \%)$, than there were in the other group, 9 $(19 \%)$.

\section{Length of hospital stay}

The mean hospitalisation time for the group of patients treated conservatively was $198 \pm 10$ days $(\mathrm{M} \pm \mathrm{SE})$, while for those treated surgically it was $222 \pm 9$ days, giving a difference of $24 \pm 14$ days). The larger economic burden caused by the longer mean hospitalisation time together with surgery expenses, in the group of patients treated surgically, should be considered when deciding the modality of treatment. Furthermore, $21 \%$ of the operated patients required a further operation to remove osteosynthesis material.

\section{Discussion}

The number of patients who suffer fractures of the spinal cord and go on to be treated surgically is high in many countries, and this is no exception in Spain. This study of a sample of 245 spinal cord injury cases shows that $55 \%$ received surgical treatment. Most of these operations took place on patients with thoracolumbar fractures, and on those with the greatest degree of fracture dislocation. This large number of surgical operations is due to the attempt to gain improvement of neurological function. This is supposed to be achieved by reduction and surgical stabilisation to prevent further vertebral dislocation. Surgery also has the aim of reducing, as much as possible, post trauma pain due to kyphosis and of reducing the amount of time spent as an inpatient. ${ }^{15}$

Favourable evolution measured over the sample as a whole was $28.4(\mathrm{Cl}=$ $20.4-36.4 \%$ ), a proportion which is not statistically different from those published by other authors. ${ }^{1,2,11}$ and is less than the figures published by others. ${ }^{10,17-19}$ 
Table VI Functional development on the Toledo scale

\begin{tabular}{lcccc} 
& Conservative & Surgical & Total & Significance \\
\hline a & 2 & 1 & 3 & \\
$\mathrm{~b}$ & 5 & 3 & 8 & $X^{2}[4]=8$ \\
$\mathrm{c}$ & 18 & 22 & 40 & $p=0.08 \mathrm{NS}$ \\
$\mathrm{d}$ & 11 & 35 & 46 & \\
$\mathrm{e}$ & 12 & 14 & 26 & \\
Total & 48 & 75 & 123 & \\
\hline
\end{tabular}

$\mathrm{a}=$ Totally dependent patient.

$\mathrm{b}=$ Partially dependent.

$\mathrm{c}=$ Independent in wheelchair.

$\mathrm{d}=$ In wheelchair and on crutches.

$\mathrm{e}=$ Totally independent in walking with or without crutches.

Our results confirm the findings of most authors, in that patients with incomplete lesions have a more favourable neurological outcome as measured on the Frankel scale than do those with a complete lesion. 2.11.16.17.19.20) The incidence of favourable neurological improvement in those with complete lesions in our study was $14 \%$ $(\mathrm{Cl}=6.5-21 \%)$, a proportion similar to those cited in other papers. ${ }^{1,11.16 .17 .20 .21}$ In those with incomplete lesions a favourable neurological evolution occurred in $66(\mathrm{Cl}=$ $50-81.4 \%$ ), a proportion similar to those published by other authors ${ }^{1.2,11,16.19 .21}$ and below the figure of $95 \%$ published by Davies et al. ${ }^{17}$

According to Guttmann ${ }^{1}$ lesions of the thoracic and thoracolumbar spinal cord which were initially complete showed a lower percentage of cases in which improvement occurred. This could be explained by the relative narrowness of the spinal canal at these levels, compared to its diameter at the cervical and lumbar levels. Nevertheless, patients with incomplete thoracic lesions do have a high percentage of improvement, and this could be explained by the supportive effect of the thoracic cage. Complete thoracic spinal injuries improved in $8 \%$ of patients in our study, while the corresponding figure for thoracolumbar injuries was $11 \%$. These proportions are lower than the $25 \%$ corresponding to lesions occurring in the cervical spinal cord, and the $50 \%$ for injuries at lumbar levels. The level of injury clearly influences neurological evolution, with the best outcome for those with cervical and lumbar injuries, as reported previously by others. ${ }^{1,2.19}$ Patients with incomplete thoracic spinal injuries improved in $80 \%$ of cases. This proportion is greater than those with injuries at other levels, and is similar to those reported by Guttmann ${ }^{1}$ and Frankel. ${ }^{2}$ At all levels the proportion of cases showing neurological improvement was statistically significantly higher for those with incomplete injuries than for patients with complete lesions, except for injuries distal to L1, where no statistically significant differences were found. This is probably due to the existence at these levels of nerve roots instead of the spinal cord.

According to Frankel, neurological evolution in incomplete lesions was clearly better in patients under 25 years of age than it was in older patients. Our results confirm those published by other authors which state that the type of fracture and the degree of wedging have no influence on the neurological outcome. ${ }^{1.2 .11 .22 .23}$ The contrary seems to be true for the degree of vertebral displacement. Some authors have found that the type of surgical intervention has no influence on the neurological outcome. ${ }^{18.24}$ There is no evidence for the hypothesis that early surgical treatment improves neurological functioning, given that neurological damage usually occurs instantly at the moment of trauma. ${ }^{15}$ Our study does not find statistically significant differences to exist between those patients who were operated on during the first 24 hours, and those 
operated afterwards. Current surgical practice is for a few vertebrae to be fused, above all the lumbar level. ${ }^{25}$

Our results confirm that reduction and stabilisation are achieved as much by using conservative as by using surgical techniques. As was reported by Harris et al ${ }^{26}$ we prefer an early reduction of fracture luxation, although no data show that this leads to improvement of neurological function. We agree that treatment should be undertaken in a specialised hospital and should be prescribed on the advice of specialists from several fields, not just by orthopaedic surgeons. ${ }^{12.18}$ Daily examination of neurological function is important, as in this way the treatment being used may be modified at any time. ${ }^{1,23}$ Correct transportation to a spinal injury unit can avoid the danger of many incomplete injuries being transformed into complete lesions. ${ }^{23.27}$

Patients who receive surgical treatment could get out of bed sooner than those treated conservatively, although surgical operations do carry a certain degree of risk. Surgically operated patients often experienced pain when the metal rods loosen after they get up from bed and many rods require to be removed at a second operation, sometimes giving rise to infection. ${ }^{1}$ Hospitalisation time was longer than that cited by other authors. ${ }^{16,17}$ This perhaps is due to the fact that we have considered the total time to be to the end of rehabilitation.

Our results support our preference for the conservative treatment of patients with vertebral fractures, as we have not found that the neurological outcome was improved by surgical measures. It should be stressed that $21 \%$ of patients operated on required a further operation to withdraw osteosynthesis material, with the subsequent added risks of surgical complications in such patients.

\section{References}

1 Guttmann L (1981) Tratamiento de las fracturas de la columna. Lesiones Medulares. Tratamiento Global e Investigacion. Jims, Barcelona: 141-180.

2 Frankel HL, Hancock DO. Hislop G, Melzak J, Michaelis LS, Ungar GH et al (1969) The value of postural reduction in the initial management of close injuries of the spine with paraplegia and tetraplegia. Part I. Paraplegia 7: $173-192$.

3 Cheshire DJE (1969) The stability of the cervical spine following the conservative treatment of fractures and fracture-dislocations. Paraplegia 7: 193-203.

4 Armis M. Suyadi A. Suprandjono R. Mochtar R (1977) Spinal fracture and its management at Gadjah Mada University Hospital, Majalah Orthopaedia Indonesia. J Indonesia Orthopaed Assoc 3: $109-117$.

5 Cloward RB (1961) Treatment of acute fractures and fracture-dislocations of the cervical spine by vertebral-body fusion. J Neurosurg 18: 201-209.

6 Raynor RB (1968) Severe injuries of the cervical spine treated by early anterior interbody fusion and ambulation. J Neurosurg 28: 311-316.

7 Norrell H, Wilson CB (1970) Early anterior fusion for injuries of the cervical portion of the spine. JAMA 214: $525-530$.

8 Roberts PH (1969) Internal metallic splintage in the treatment of traumatic paraplegia. Injury 1: 4-11.

9 Holdsworth FW (1970) Fractures, dislocations and fracture-dislocations of the spine. J Bone Joint Surg 52A: $1534-1551$

10 MacBride GG (1989) Cotrel-Dubousset road in spinal fractures. Paraplegia 27: 440-449.

11 Burke DC. Murray DD (1976) The management of thoracic and thoracolumbar injuries of the spine with neurological involvement. J Bone Joint Surg 58B: 72-78.

12 Bedbrook GM (1979) Spinal injuries with tetraplegia and paraplegia. J Bone Joint Surg 61B: 267-284.

13 Schlesselman JJ (1982) Case-Control Studies. Oxford University Press, New York: 194-206.

14 Holdsworth FW (1963) Fractures, dislocations and fractures-dislocations of the spine. J Bone Joint Surg 45B: $6-20$.

15 Dickson RA (1992) Spinal injuries: early surgical treatment. Paraplegia 30: 43-45.

16 Dickson JH, Harrington PR. Erwin WD (1978) Results of reduction and stabilization of the severely fractured thoracic and lumbar spine. J Bone Joint Surg 60A: 799-805.

17 Davies WE, Morris JJ. Hill V (1980) An analysis of conservative (non surgical) management of thoracolmbar fractures and fracture-dislocations with neuronal damage. J Bone Joint Surg 62A: 1324-1328.

18 Carlsson C-A, Pellettieri L (1987) Treatment of spinal cord injuries in the thoracolumbar region. Scand $J$ Rehabil Med 19: 71-75.

19 Biering-Sorensen F. Pedersen V. Clausen S (1990) Epidemiology of spinal cord lesions in Denmark. Paraplegia 28: $105-118$. 
20 Young JS, Dexter WR (1978) Neurological recovery distal to the zone of injury in 172 cases of close traumatic spinal cord injury. Paraplegia 16: $39-49$.

21 Bedbrook G (1980) Recovery of spinal cord function. Paraplegia 18: 315-323.

22 Phillippi R, Kuhn W, Zach GA, Jacob-Chia D, Dolfus P, Moll JP (1980) Survey of the neurological evolution of 300 spinal cord injuries seen within 24 hours after injury. Paraplegia 18: 337-346.

23 Brooks ME (1992) Conservative versus surgical treatment of the cervical and thoracolumbar spine in spinal trauma. Paraplegia 30: 46-49.

24 Osebold WR, Weinstein SL, Sprague BL (1981) Thoracolmbar spine fractures. Results of treatment. Spine 6: $13-34$.

25 Brown DJ (1992) Spinal cord injuries: the last decade and the next. Paraplegia 30: 77-82.

26 Harris P, Karmi MZ, McClemont E, Matlhoko D, Paul S (1980) The prognosis of patients sustaining severe cervical spine injury (C2-C7 inclusive). Paraplegia 18: 324-330.

27 Hachen HJ (1974) Emergency transportation in the event of acute spinal cord lesions. Paraplegia 12: 33-77. 